\title{
Radio-induced incoherent scatter ion line enhancements with wide altitude extents in the high-latitude ionosphere
}

\author{
A. Senior, ${ }^{1}$ M. T. Rietveld, ${ }^{2}$ I. Häggström, ${ }^{3}$ and M. J. Kosch ${ }^{1,4}$ \\ Received 4 February 2013; accepted 19 February 2013.
}

[1] Apparent large electron density enhancements deduced from incoherent scatter radar observations during recent high power radio wave injection experiments at the European Incoherent Scatter Scientific Association (EISCAT) facility near Tromsø, Norway have been previously reported. These apparent enhancements extend over a wide altitude range, including the topside ionosphere. Observational evidence is presented, which shows that these apparent density enhancements appear to exhibit aspect-sensitive backscattering and are not associated with corresponding changes in the frequency of the incoherent scatter plasma line. It is concluded that although an enhancement in the power of the incoherent scatter ion line is observed, it is not the result of an enhancement in the plasma density, but must be due to some other unknown mechanism. Citation: Senior, A., M. T. Rietveld, I. Häggström and M. J. Kosch (2013), Radio-induced incoherent scatter ion line enhancements with wide altitude extents in the high-latitude ionosphere, Geophys. Res. Lett., 40, doi:10.1002/grl.50272.

\section{Introduction}

[2] When a high power high frequency (HF) radio "pump" wave interacts with the ionospheric plasma, one of the results can be a change in the electron density in the vicinity of the reflection altitude of the wave. Using the Arecibo HF facility and incoherent scatter radar, Djuth et al. [1987] and Duncan et al. [1988] found density depletions of as much as 50\%. Stocker et al. [1992] found both density depletions and enhancements on the order of $10 \%$ using the high-latitude European Incoherent Scatter Scientific Association (EISCAT) facility. These effects were thought to be due to the plasma response to the enhanced electron temperature. Pedersen et al. [2010, 2011] observed large increases in electron density in ionograms when using the High Frequency Active Auroral Research Program (HAARP) facility. These increases were associated with strong thermospheric optical emissions and were attributed to ionization by electrons accelerated by plasma turbulence. In all these experiments, the pump wave was polarized in the O-mode.

[3] Blagoveshchenskaya et al. [2011a, 2011b] presented EISCAT UHF radar observations of large (up to 30\%) electron density enhancements during $\mathrm{X}$-mode pumping. The

\footnotetext{
${ }^{1}$ Department of Physics, Lancaster University, Lancaster, UK.

${ }^{2}$ EISCAT Scientific Association, Ramfjordmoen, Norway.

${ }^{3}$ EISCAT Scientific Association, Kiruna, Sweden.

${ }^{4}$ School of Chemistry and Physics, University of KwaZulu-Natal, Durban, South Africa.

Corresponding author: A. Senior, Department of Physics, Lancaster University, Lancaster LA1 4YB, UK. (a.senior@lancaster.ac.uk)

(C)2013. American Geophysical Union. All Rights Reserved. 0094-8276/13/10.1002/grl.50272
}

enhancements were detectable over a wide altitude region of $\sim 125 \mathrm{~km}$. The observation of such effects with an X-mode pump is surprising since an X-mode wave reflects below the altitudes at which various plasma instabilities can be excited and which are responsible for many of the dramatic effects of O-mode pumping [Robinson, 1989].

[4] In this article, further observations of apparent large electron density enhancements during both $\mathrm{O}$ - and $\mathrm{X}$-mode pumping at EISCAT are presented. However, the evidence from the experiments suggests that the interpretation of the observations as enhancements of the electron density, as indicated by the standard analysis of the incoherent scatter radar data, is almost certainly incorrect.

\section{Instrumentation and Observations}

[5] The EISCAT HF Facility [Rietveld et al., 1993] is located near Tromsø, Norway $\left(69.58^{\circ} \mathrm{N}, 19.21^{\circ} \mathrm{E}\right)$. The facility can radiate a high-frequency (HF) radio wave in the frequency range 4-8 MHz with an effective radiated power (ERP) of up to $\sim 1 \mathrm{GW}$. The beam may be steered up to about $30^{\circ}$ away from the zenith in the north-south plane. Arbitrary elliptical polarization is possible, including the circular ionospheric O- and X-modes. The beam width and maximum power are a function of frequency. The ERP quoted here was estimated using a model based on the NEC2 code assuming a perfectly conducting ground.

[6] The EISCAT UHF radar [Rishbeth and van Eyken, 1993] located about $500 \mathrm{~m}$ from the HF facility is an incoherent scatter radar operating at $930 \mathrm{MHz}$. The antenna is a $32 \mathrm{~m}$ parabolic dish giving a beam width of $0.6^{\circ}$ at half-maximum power. It is fully steerable in azimuth and elevation. Two remote receivers with identical antennas were located at Kiruna, Sweden $\left(67.86^{\circ} \mathrm{N}, 20.43^{\circ} \mathrm{E}\right)$ and Sodankylä, Finland $\left(67.36^{\circ} \mathrm{N}, 26.63^{\circ} \mathrm{E}\right)$. These receivers ceased operating at $930 \mathrm{MHz}$ in 2011 . The UHF radar data presented here has been analyzed using version 8.7 of the GUISDAP software [Lehtinen and Huuskonen, 1996] using an integration time of $30 \mathrm{~s}$. The electron densities were calibrated against $f_{O} \mathrm{~F}_{2}$ measured by the EISCAT Dynasonde. Local time at Tromsø is UT+1.3 h.

[7] From 13:10 until 14:50 UT on 18 October 2012, the $\mathrm{HF}$ facility was operated on $7.953 \mathrm{MHz}$ with the beam directed field-aligned (actually $12^{\circ}$ south of the zenith). The ERP is estimated to have been $840 \pm 7 \mathrm{MW}$. The uncertainty is the standard deviation of the ERPs of the individual pulses. The pump wave was pulsed $300 \mathrm{~s}$ on, $300 \mathrm{~s}$ off with the polarization changing between $\mathrm{O}$ - and $\mathrm{X}$-mode on successive pulses, making an overall cycle of $1200 \mathrm{~s}$.

[8] During each pump pulse, the UHF radar beam was pointed field-aligned for the first $120 \mathrm{~s}$, then sequentially $1^{\circ}$ higher and lower in elevation than field-aligned for $60 \mathrm{~s}$ each 


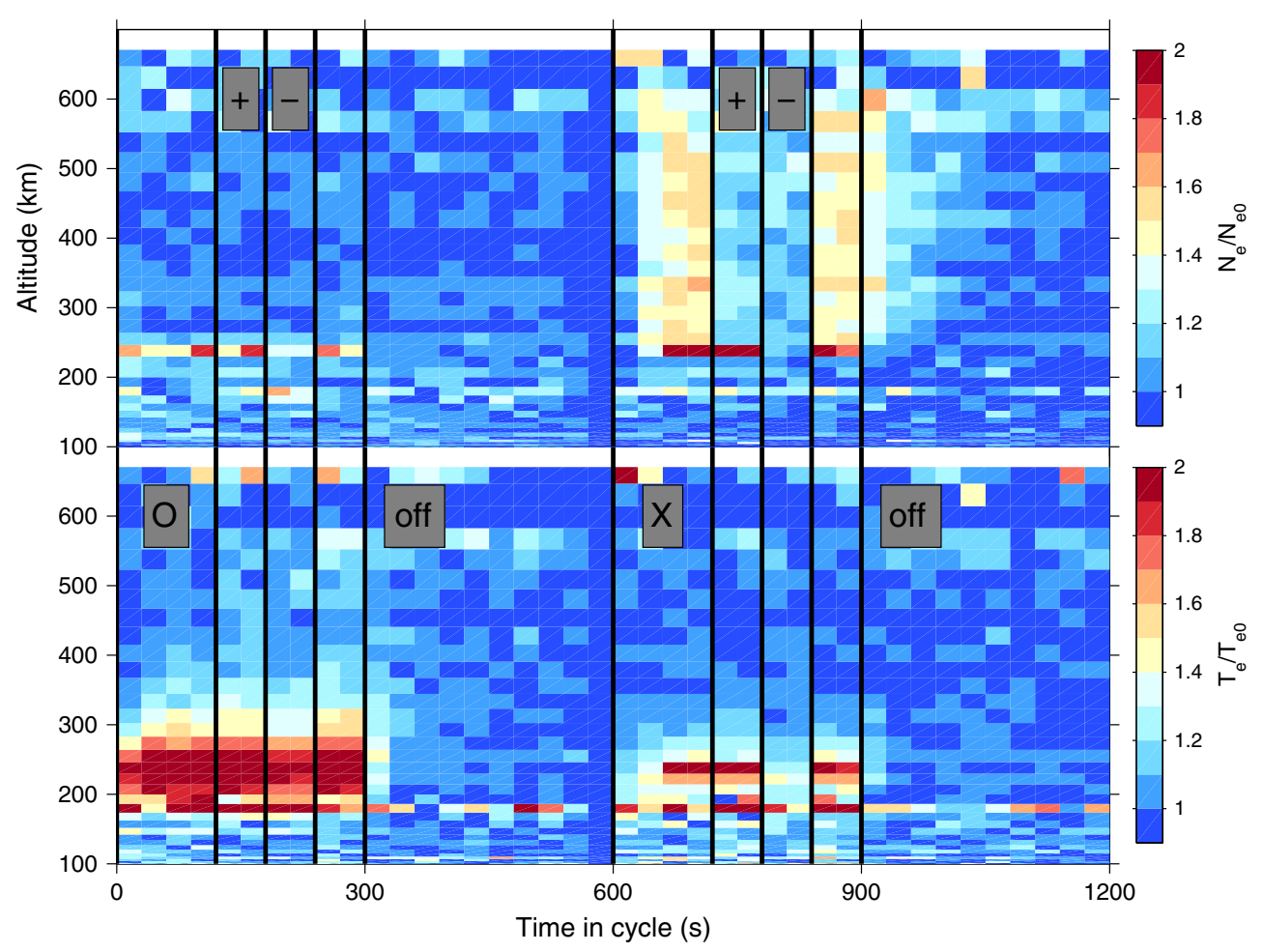

Figure 1. (top) The median of the ratio of the electron density to its undisturbed value over all five heating cycles. (bottom) The same as the top, but for the electron temperature. The pump wave polarization is indicated by ' $\mathrm{O}$ ' and ' $\mathrm{X}$ ' as appropriate. The periods where the radar beam was pointed $1^{\circ}$ higher and lower in elevation than the magnetic field-aligned direction are denoted by '+' and '-', respectively.

and finally returning to field-aligned for $60 \mathrm{~s}$ before the end of the pulse. The beam then remained field-aligned while the pump was off. The field-aligned direction for the radar was $12.5^{\circ}$ zenith angle, $186.2^{\circ}$ azimuth.

[9] Figure 1 shows the median over all five cycles of the ratios of the electron density $N_{e}$ and temperature $T_{e}$ to their undisturbed values $N_{e 0}, T_{e 0}$ as a function of altitude and the time within the $1200 \mathrm{~s}$ cycle. The undisturbed values were taken as the values from the final $30 \mathrm{~s}$ of the pump-off period before the X-mode pulse.

[10] During the O-mode pulses, there is no evidence of a change in $N_{e}$ except for a narrow region near $240 \mathrm{~km}$. This is the result of an enhancement of the ion line by ion acoustic waves excited by parametric instabilities close to the reflection altitude of the pump wave [Fejer, 1979; Stubbe et al., 1992]. On the other hand, there is a strong enhancement of $T_{e}$ extending above and below this altitude as is commonly observed with O-mode heating [Rietveld et al., 2003]. There is only slight evidence of a reduction in the temperature enhancement when the radar beam is pointed $1^{\circ}$ lower in elevation than field-aligned.

[11] During the X-mode pulses, there is a strong enhancement of $N_{e}$, which extends from approximately the pump reflection altitude to the limit of the radar's measurement above $600 \mathrm{~km}$. The enhancement develops over the first $120 \mathrm{~s}$ of the pump pulse reaching a level of $N_{e} / N_{e 0} \approx 1.5$, which appears to be approximately independent of altitude. After the pump is switched off, the enhancement decays to the undisturbed level within about $90 \mathrm{~s}$. It is also apparent that the enhancement is greatly reduced when the radar beam is pointed $1^{\circ}$ in elevation away from field-aligned, falling to a level of $N_{e} / N_{e 0} \approx 1.2$. As in the O-mode case, there is a narrow region of strongly enhanced density around $240 \mathrm{~km}$. According to the ERP model, in addition to the wanted Xmode wave, a weaker O-mode component with an ERP of $\sim 4 \mathrm{MW}$ would have been present. This may be sufficient to excite ion acoustic waves. This enhancement seems to be absent when the radar is pointing $1^{\circ}$ below field-aligned in elevation.

[12] The electron temperature is also enhanced during the $\mathrm{X}$-mode pulses, but much less so than during the O-mode pulses. This is consistent with the idea that an O-mode pump excites electrostatic upper-hybrid waves whose large electric fields strongly heat the electrons, but that an X-mode pump cannot do so [Robinson, 1989]. The narrow band of highly enhanced electron temperature around $240 \mathrm{~km}$ is again likely to be due to excited ion acoustic waves.

[13] Figure 2 compares mean radar ion line spectra from the end of each X-mode pulse and immediately before each $\mathrm{X}$-mode pulse during the 13:10-14:50 interval. The spectra have been corrected for the change in radar transmitter power due to the operation of the HF facility. The enhancement in the power spectrum is clear, but it is also evident that when the enhanced spectrum is scaled down so that its total power matches that of the unenhanced spectrum (a factor of 1.5), its shape corresponds very closely with that of the spectrum taken before the pump pulse. This is consistent with the fitted plasma parameters, which show no significant change except in the electron density at this altitude.

[14] From 14:50 until 16:00 UT on 18 October 2012, the HF facility continued to operate on $7.953 \mathrm{MHz}$. The pump was pulsed on for $360 \mathrm{~s}$ and off for $240 \mathrm{~s}$ and polarized in 


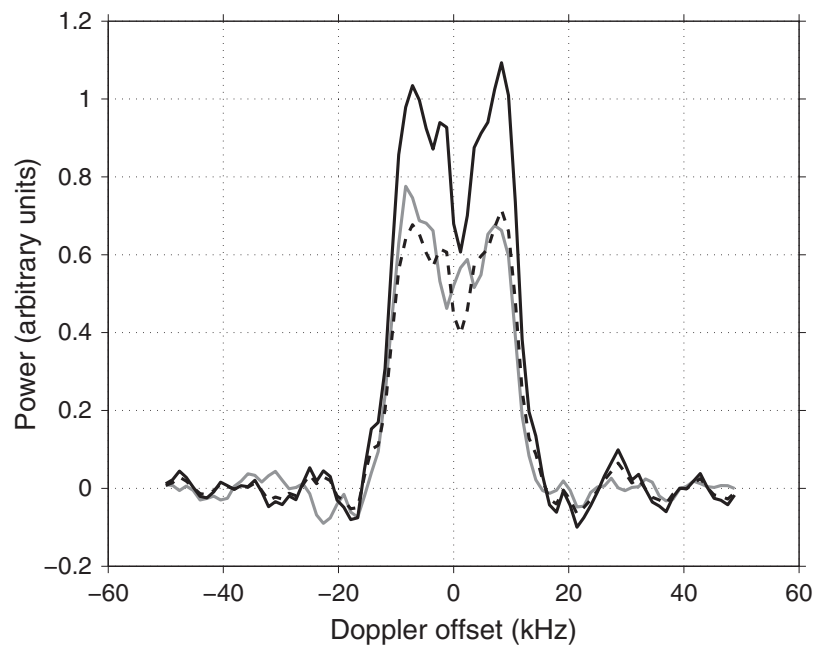

Figure 2. UHF radar ion-line spectra during the interval 13:10-14:50 UT on 18 October 2012 at an altitude of $300 \mathrm{~km}$. Each spectrum is the mean over all five heating cycles. The gray curve is from the $30 \mathrm{~s}$ integrations immediately before the $\mathrm{X}$-mode pulses. The black curve is from the final $30 \mathrm{~s}$ integration of the X-mode pulses. The dashed black curve is the black curve scaled to have the same total power as the gray curve.

the X-mode. During each $360 \mathrm{~s}$ pump pulse, the pump power was increased every $120 \mathrm{~s}$. For the pulses beginning at 15:10, 15:20 and 15:30 UT, the power levels for each $120 \mathrm{~s}$ step were $224 \pm 26,453 \pm 4$ and $827 \pm 5 \mathrm{MW}$. (Technical problems with the HF facility were experienced during the pulses at 14:50 and 15:00 UT and so these pulses are not discussed here). For the pulse beginning at 15:40 UT, the power levels were 15, 79 and $168 \mathrm{MW}$, and for the pulse beginning at 15:50 UT, they were 41, 82 and $166 \mathrm{MW}$.

[15] In Figure 3, the downshifted plasma line spectra from the UHF radar are plotted versus time for altitudes of 321 and $339 \mathrm{~km}$. The entire interval from 13:10-16:00 UT is shown, encompassing both the alternating $\mathrm{O}$ - and $\mathrm{X}$-mode pulses and the power-stepped X-mode pulses. The spectra for each altitude come from two separate plasma line channels covering Doppler frequency offsets of -9.65 to $-7.15 \mathrm{MHz}$ and -7.25 to $-4.75 \mathrm{MHz}$, respectively. The dark vertical stripes in the spectrogram for $320 \mathrm{~km}$, which begin at 14:20 UT and continue until 15:35 UT, are caused by leakage of strong backscatter from Langmuir waves near $7.953 \mathrm{MHz}$ excited directly by the pump wave during the pump pulses. Choosing a lower altitude results in this contamination covering most of the interval of interest, whereas a higher altitude results in the plasma line frequency being too low for this channel. The spectrogram for $339 \mathrm{~km}$ altitude is free from this contamination, but the plasma line is harder to detect prior to $\sim 14: 30$ UT when it is close to the edge of the channel. As in the ion line case, the spectra have been corrected for radar transmitter power variations.

[16] The blue curves in Figure 3 indicate the plasma frequency corresponding to the electron density derived from the ion line analysis for each altitude. The large increases during the $\mathrm{X}$-mode pump pulses, with reductions when the radar is scanned $\pm 1^{\circ}$ in elevation from field-aligned are clearly seen and correspond to the electron density enhancements already discussed. It is seen that the density enhancements continue to occur during the power-stepped pulses, even at the low powers in the final two pulses. However, it is striking that despite these supposed large increases in plasma density and plasma frequency, the frequency of the plasma line, corresponding to the frequency of Langmuir waves with wave number twice that of the UHF radar, shows no appreciable change.

[17] During the O-mode pump pulses, a slight increase in the plasma line frequency can be seen, particularly at $321 \mathrm{~km}$. These increases are to be expected from the increases in $T_{e}$ at $321 \mathrm{~km}$ indicated in Figure 1. Similar changes become evident at $339 \mathrm{~km}$ during the X-mode pulses after 15:00 UT.

[18] Figure 4 shows field-aligned (zenith angle $12.9^{\circ}$, azimuth $183.3^{\circ}$ ) UHF radar measurements from an experiment performed on 11 November 2001. The electron density enhancements coincident with HF pumping are clear in the top panel. For the whole interval shown, the pump frequency remained at $5.423 \mathrm{MHz}$, the polarization O-mode and the beam directed field-aligned $\left(12^{\circ}\right.$ south of vertical). Prior to 17:18 UT, high-gain antenna Array 1 was used. Low-gain Array 2 was used after this time. The gray line in the bottom panel of Figure 4 shows the pump cycle and relative ERP. Prior to 15:20 UT tune-up and calibration transmissions occurred. From 15:20-16:06 UT, the pump power was stepped down in the sequence $546 \pm 1,249 \pm 2,123 \pm 3$ and $64 \pm 2 \mathrm{MW}$ with a $120 \mathrm{~s}$ on, $120 \mathrm{~s}$ off cycle. Two long pump pulses occurred at 16:11:00-16:15:30 UT and 16:22:30-16:32:00 UT. Between these, the pump was cycled $30 \mathrm{~s}$ on, $30 \mathrm{~s}$ off. The ERP in all these cases was $\sim 540 \mathrm{MW}$. From 16:34-17:16 UT, the pump power was $531 \pm 4 \mathrm{MW}$ and the cycle $120 \mathrm{~s}$ on, $120 \mathrm{~s}$ off.

[19] Since this experiment took place in 2001, the UHF remote receivers at Kiruna and Sodankylä were available, and data were recorded at both sites. The Kiruna receiver beam was directed to intersect the Tromsø transmitter beam at an altitude of $292 \mathrm{~km}$. The Sodankylä beam intersected the Troms $\varnothing$ beam at $301 \mathrm{~km}$. The bottom panel of Figure 4 compares the electron densities observed at Kiruna and Sodankylä with that at a similar altitude $(302 \mathrm{~km})$ observed from Tromsø. As expected from the top panel, the curve for Tromsø clearly shows the electron density enhancements during some of the pump pulses. However, in contrast, no corresponding enhancements are seen in the curves for Kiruna or Sodankylä. The relative errors in the electron densities over the interval are $\sim 2-3 \%$ for Tromsø, $\sim 1-2 \%$ for Kiruna and $\sim 1-3 \%$ for Sodankylä.

[20] The middle panel of Figure 4 shows the electron temperature profiles. The behavior seen here is typical of that during O-mode pumping of the F-region, namely strong electron temperature enhancements peaking near to the reflection altitude of the pump wave. During the pump power-stepping cycles from 15:20-16:06 UT, it can be seen that the temperature enhancement increases with pump power. Unlike the electron densities, the electron temperatures measured at the remote sites agreed well with those measured at Tromsø at the corresponding altitude.

\section{Discussion and Conclusion}

[21] The Tromsø UHF radar beam scanning results from 18 October 2012 (Figure 1) suggest that the regions of enhanced ion line backscatter, interpreted by the analysis 

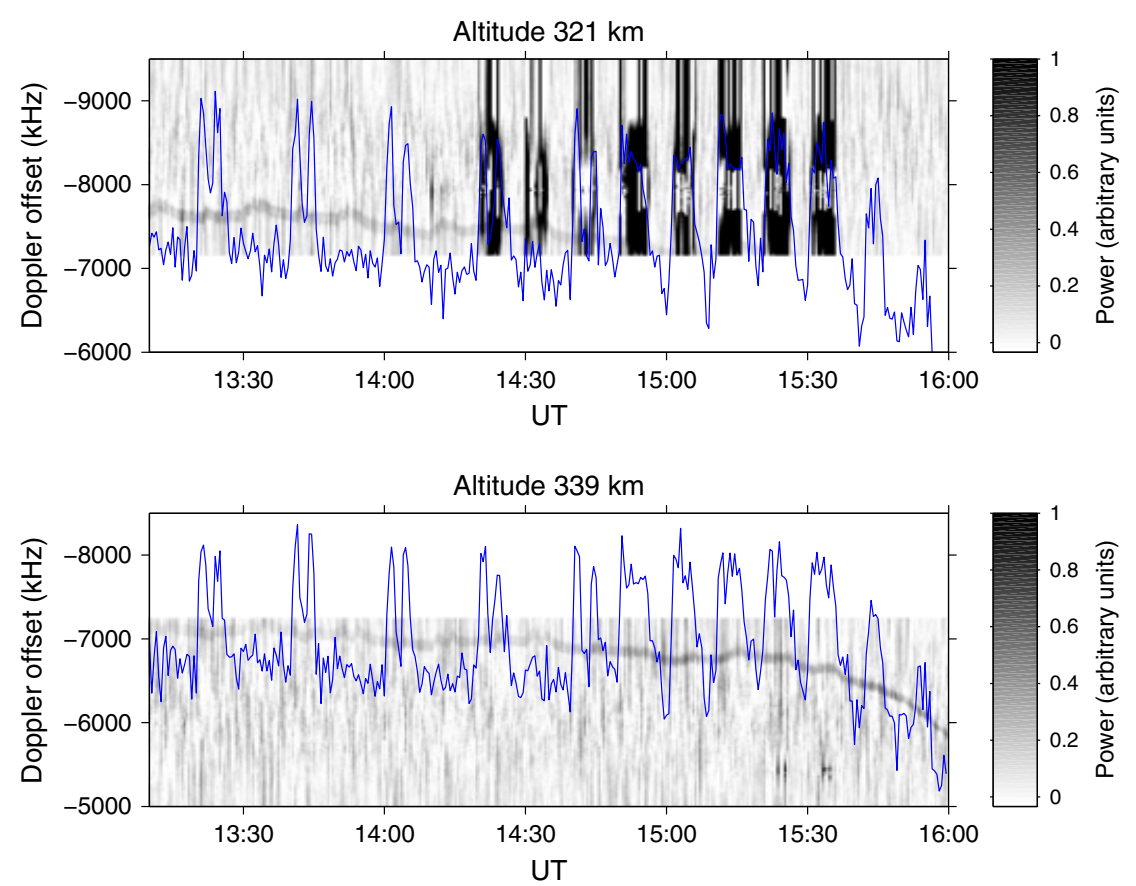

Figure 3. In gray scale, the UHF radar downshifted plasma line spectra versus time. The blue curves indicate the plasma frequency corresponding to the electron density given by the ion line analysis. (top) Spectra and plasma frequency for an altitude of $321 \mathrm{~km}$. (bottom) The same for an altitude of $339 \mathrm{~km}$.

procedure as enhanced electron density, are either limited to very narrow regions across the geomagnetic field or are aspect-sensitive. During the experiment on 18 October 2012, the HF pump beam was $5^{\circ}$ wide at halfmaximum power. At $1^{\circ}$ away from the beam boresight, the power would have been reduced to $\sim 90 \%$ of maximum. Although it is not immediately clear from Figure 3, the results of power-stepping the pump indicated that although
15-41 MW was insufficient to excite clear density enhancements, $\sim 80 \mathrm{MW}$ was sufficient. That the density enhancement was reduced by half at $1^{\circ}$ in elevation away from field-aligned does not seem to be explicable in terms of the reduced HF power flux.

[22] The results from 11 November 2001 (Figure 4) show that even when the density enhancement observed from Tromsø is very large (for example, 15:36, 15:40, 15:52

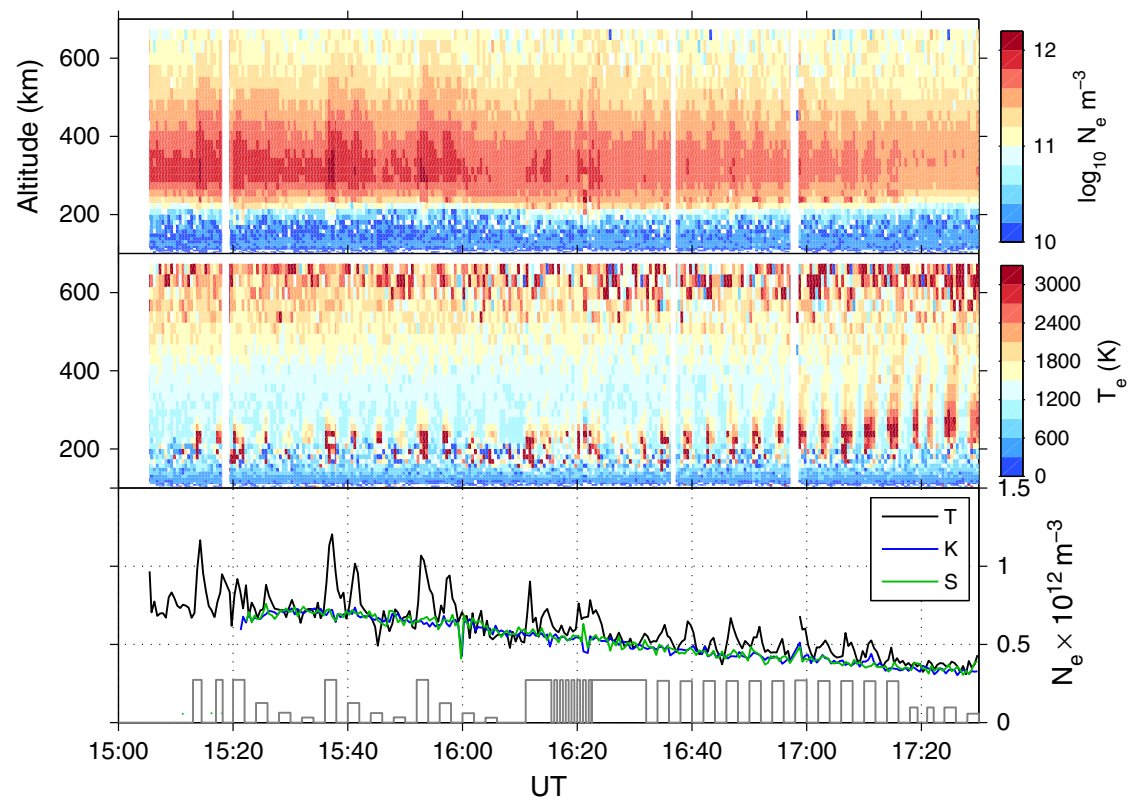

Figure 4. (top) Time series of electron density profiles from the UHF radar on 11 November 2001. (middle) The corresponding time series of electron temperature profiles. (bottom) Time series of electron density at an altitude of $302 \mathrm{~km}$ from Tromsø (black), at $291 \mathrm{~km}$ from Kiruna (blue) and at $300 \mathrm{~km}$ from Sodankylä (green). The grey bars indicate the relative pump power. 
and 15:56 UT), there is no evidence of any enhancement observed by either remote receiver. The angles between the Tromsø beam and those from Kiruna and Sodankylä were $37^{\circ}$ and $55^{\circ}$ respectively. It should be noted that the electron densities obtained from GUISDAP for Kiruna were multiplied by a factor of 0.7 in order to obtain quantitative agreement with the densities from Tromsø in the plot. However, this scaling was applied to the whole data set and would not affect time-varying changes due to HF pumping. When checking the geometry of the receiver-transmitter beam intersections, it was found that although the Kiruna beam intersected the Tromsø beam well within their beam widths $\left(0.6^{\circ}\right.$ full width at half-maximum gain at all sites $)$, the Sodankylä beam appeared to miss the Tromsø beam by approximately its beam width. This could have been due to inaccurately recorded antenna azimuth and elevation angles at Sodankylä during this experiment or a mistake in programming. However, if it was correct and if the region of enhanced backscatter was indeed of very limited extent across the magnetic field, then it is possible that Sodankylä would have failed to observe it. Taken together, the Troms $\varnothing$ beam-swinging and remote site observations tend to favor the hypothesis of aspect-sensitive scattering.

[23] The behavior of the ion line spectrum in the enhanced region (Figure 2) appears to be consistent with its interpretation by GUISDAP as corresponding to an increase in plasma density. However, this interpretation is hard to reconcile with the behavior of the plasma line (Figure 3). The plasma line is backscatter from Langmuir waves, in this case propagating along the magnetic field direction, whose frequency $\omega$ satisfies the following dispersion relation, which can be obtained from the full dispersion relation by assuming electrostatic waves and parallel propagation [e.g., Baumjohann and Treumann, 1996, Chap. 10]

$$
\omega^{2}=\omega_{p}^{2}+\omega_{p e}^{2} \int_{0}^{\infty} 2 \pi v_{\perp} \mathrm{d} v_{\perp} \int_{-\infty}^{\infty} \frac{k_{\|} v_{\|}^{2} \frac{\partial f}{\partial v_{\|}}}{\omega-k_{\|} v_{\|}} \mathrm{d} v_{\|}
$$

where $\omega_{p}, \omega_{p e}$ are the plasma frequency and electron plasma frequency, $k$ is the Langmuir wave number, $f$ is the electron distribution function and the subscripts $\perp$ and $\|$ denote components perpendicular and parallel to the magnetic field respectively. This expression is strictly valid only in equilibrium conditions, but it is clear from Figure 1 that an equilibrium state has been reached by $\sim 120$ s after pumpon and that the rate of change at pump-on and pump-off is slow compared to the frequency of the Langmuir waves. According to (1), changes in the plasma frequency would be expected to produce corresponding changes in the plasma line frequency unless they were compensated by changes in the shape of the electron distribution function through the integral term. It is well known from observations of thermospheric optical emissions during HF pumping that the electron distribution function can be modified [Kosch et al., 2007]. Yet, although it cannot be ruled out, it would be truly remarkable if the electron distribution function was changed in just such a way as to compensate for the effect of changing the plasma density.

[24] Due to technical limitations of the UHF radar, only the downshifted plasma line was measured. The plasma line observations alone therefore cannot rule out the existence of a downward electron drift within the radar beam, which Doppler shifts the plasma line spectrum upwards in frequency, canceling the downward shift due to the increased density. It is unclear what might drive such a current, but its required magnitude is simple to estimate. From Figure 3, the Doppler shift required would be on the order of $2 \mathrm{MHz}$. For $v \ll c$, the backscatter Doppler shift is given by $\Delta f=$ $2(v / c) f$ where $v$ is the target speed and $f$ is the transmitted frequency. Hence, we have $v=3.2 \times 10^{5} \mathrm{~ms}^{-1}$. With an ambient electron density of $6 \times 10^{11} \mathrm{~m}^{-3}$, this gives a current density of $J=30 \mathrm{~mA} \mathrm{~m}^{-2}$ and with a field-parallel electron conductivity of $\sigma \approx 100 \mathrm{Sm}^{-1}$, the ohmic heating rate would be $P=J^{2} / \sigma=9 \mu \mathrm{W} \mathrm{m} m^{-3}$. This is $\sim 3$ orders of magnitude higher than heating rates normally found in the ionosphere [Schunk and Nagy, 1978] and would have been easily noticeable in the electron temperature. Therefore, it is safe to conclude that this explanation for the lack of frequency change in the downshifted plasma line can be ruled out.

[25] Ekeberg et al. [2010, 2012] presented observations of naturally occurring ion line enhancements observed with the EISCAT Svalbard radar. Similar to the enhancements reported here (Figure 2), their enhancements were uniform across the ion line spectrum. They interpreted these enhancements using a theory of ion acoustic solitary waves propagating perpendicular to the magnetic field and the radar beam compressing the plasma and therefore increasing its density. However, this theory does not seem to explain all the phenomena reported here. If the density in the radar beam really was increased, even if inhomogenously by small-scale structures, one would expect that the plasma line backscatter would show a spread of frequencies corresponding to the spread of densities. As Figure 3 shows, this behavior was not observed. It is also unclear why the enhancement would cease to be observed at small angles of the radar beam from the geomagnetic field line.

[26] In summary, it seems reasonable to conclude that the apparent electron density enhancements presented here and possibly those previously reported by [Blagoveshchenskaya et al., 2011a, 2011b] do not in fact correspond to true enhancements in electron density. Instead, it appears that the incoherent scatter ion line spectrum is enhanced in power by some mechanism, which does not involve a change in plasma density and which preferentially scatters the radar wave back along the magnetic field line. At present, the authors are unable to offer a physical explanation of this phenomenon.

[27] Acknowledgments. A.S. is supported by UK NERC grant NE/I027231/1. EISCAT is an international association supported by China, Finland, Japan, Norway, Sweden and the UK We thank A. J. Kavanagh for operating the UHF radar in November 2001.

\section{References}

Baumjohann, W., and R. A. Treumann (1996), Basic Space Plasma Physics, Imperial College Press, London.

Blagoveshchenskaya, N. F., T. D. Borisova, T. K. Yeoman, M. T. Rietveld, I. M. Ivanova, and L. J. Baddeley (2011a), Artificial small-scale fieldaligned irregularities in the high latitude $\mathrm{F}$ region of the ionosphere induced by an X-mode HF heater wave, Geophys. Res. Lett., 38, L80,302, doi:10.1029/2011GL046724.

Blagoveshchenskaya, N. F., T. D. Borisova, M. T. Rietveld, T. K. Yeoman, D. M. Wright, M. Rother, H. Lühr, E. V. Mishin, and C. Roth (2011b), Results of Russian experiments dealing with the impact of powerful HF radio waves on the high-latitude ionosphere using the EISCAT facilites, Geomagn. Aeron., 51, 1109-1120, doi:10.1134/S0016793211080160.

Djuth, F. T., B. Thidé, H. M. Ierkic, and M. P. Sulzer (1987), Large F-region electron temperature enhancements generated by high-power HF radio waves, Geophys. Res. Lett., 14, 953-956. 


\section{SENIOR ET AL.: INCOHERENT BACKSCATTER ENHANCEMENTS}

Duncan, L. M., J. P. Sheerin, and R. A. Behnke (1988), Observations of ionospheric cavities generated by high-power radio waves, Phys. Rev. Lett., 61, 239-242.

Ekeberg, J., G. Wannberg, L. Eliasson, and K. Stasiewicz (2010), Ionacoustic solitary waves and spectrally uniform scattering cross section enhancements, Ann. Geophys., 28, 1299-1306, doi:10.5194/angeo-281299-2010.

Ekeberg, J., G. Wannberg, L. Eliasson, and I. Häggström (2012), Soliton-induced spectrally uniform ion line power enhancements at the ionospheric F region peak, Earth Planets Space, 64, 605-611, doi: 10.5047/eps.2012.02.005.

Fejer, J. A. (1979), Ionospheric modification and parametric instabilities, Rev. Geophys. Space Phys., 17, 135-153.

Kosch, M. J., T. Pedersen, M. T. Rietveld, B. Gustavsson, S. M. Grach, and T. Hagfors (2007), Artificial optical emissions in the high-latitude thermosphere induced by powerful radio waves: An observational review, Adv. Space Res., 40, 365-476, doi:10.1016/j.asr.2007.02.061.

Lehtinen, M. S., and A. Huuskonen (1996), General incoherent scatter analysis and GUISDAP, J. Atmos. Terr. Phys., 58, 435-452.

Pedersen, T., B. Gustavsson, E. Mishin, E. Kendall, T. Mills, H. C. Carlson, and A. L. Snyder (2010), Creation of artificial ionospheric layers using high-power HF waves, Geophys. Res. Lett., 37, L02,106, doi: 10.1029/2009GL041895.

Pedersen, T., M. McCarrick, B. Reinisch, B. Watkins, R. Hamel, and V. Paznukhov (2011), Production of artificial ionospheric layers by frequency sweeping near the 2nd gyroharmonic, Ann. Geophys., 29, 47-51, doi:10.5194/angeo-29-47-2011.

Rietveld, M. T., H. Kohl, H. Kopka, and P. Stubbe (1993), Introduction to ionospheric heating experiments at Troms $\varnothing-$ I. Experimental overview, J. Atmos. Terr. Phys., 55, 577-599.

Rietveld, M. T., M. J. Kosch, N. F. Blagoveshchenskaya, V. A. Kornienko, T. B. Leyser, and T. K. Yeoman (2003), Ionospheric electron heating, optical emissions, and striations induced by powerful HF radio waves at high latitudes: Aspect angle dependence, J. Geophys. Res., 108(A4), 1141, doi:10.1029/2002JA009543.

Rishbeth, H., and A. P. van Eyken (1993), EISCAT - Early history and the first ten years of operation, J. Atmos. Terr. Phys., 55(4-5), 525-542.

Robinson, T. R. (1989), The heating of the high latitude ionosphere by high power radio waves, Phys. Rep, 179, 79-209.

Schunk, R. W., and A. F. Nagy (1978), Electron temperatures in the F region of the ionosphere: Theory and observations, Rev. Geophys. Space Phys. 16(3), 355-399.

Stocker, A. J., F. Honary, T. R. Robinson, T. B. Jones, P. Stubbe, and H. Kopka (1992), EISCAT observations of large scale electron temperature and electron density perturbations caused by high power HF radio waves, J. Atmos. Terr. Phys., 54, 1555-1572.

Stubbe, P., H. Kohl, and M. T. Rietveld (1992), Langmuir turbulence and ionospheric modification, J. Geophys. Res., 97(A5), 6285-6297. 